\title{
Automobility, Vélomobility, American Mobility: An Exploration of the Bicycle Tour
}

\author{
MICHAEL W. PESSES* \\ Department of Geography/GIS, Antelope Valley College, Lancaster, California, USA
}

ABSTRACT Using the framework of 'automobility' as outlined by Sheller and Urry, this article uses the bicycle tour to explore one way the middle class mediates the automobile's domi-

AQ1 nance of the American landscape. The material history of the American road is first placed into the current automobilities discourse and then used to situate the bicycle tour. The romantic notion of lost public place in the city is seen as a driving force for escaping on two wheels into the 'authentic' American landscape. As the long distance bicycle tourist experiences the material landscape in a new way, the idea of a lost public landscape is challenged and the tourist is able to come to terms with his or her place in the dominant mobility assemblage of human and machine. The result is not a full resistance of the automobile, but a new conception of place and mobility.

KEY WoRDS: Automobility, vélomobility, bicycling, America

Pedestrians and cyclists, to a significant extent, are confined to small slivers of the urban public, while many public-transport users are relatively disenfranchised and excluded from full citizenship. Only those moving (however slowly) in cars, taxis, and trucks are public within a system where public spaces have been democratically seized, through notions of individual choice and personal flexibility, and then turned into the 'iron-cages' that deform public roads and the people disciplined within them. (Sheller \& Urry, 2000, p. 754, emphasis in the original).

Which do we value more, a sense of place or a sense of freedom? (Jackson, 1997 [1994], p. 250).

Correspondence Address: Michael W. Pesses, Department of Geography/GIS, Antelope Valley College,

AQ2 3041 West Avenue K, Lancaster, California 93536-5426, USA. Email: mpesses@avc.edu

1745-0101 Print/1745-011X Online/10/010001-24 (C) 2010 Taylor \& Francis

DOI: $10.1080 / 17450100903435029$ 


\section{M. W. Pesses}

\section{Introduction}

In 2000, Sheller and Urry criticized the lack of work done on the social side of the automobile, especially in urban studies. Previous work had been focused on the automobile as a socially neutral object or an evil one hell-bent on destroying a past way of urban life (Sheller \& Urry, 2000, p. 738). Their argument was that urban studies needed to explore the idea that 'the car-driver is a "hybrid" assemblage' and that as such these hybrids are 'only able to roam in certain time-space scapes' (p. 739). Their call has been heeded; since the publication of their article, the social sciences have seen 10 an increase in work on automobilities (see for instance Böhm et al., 2006; Featherstone et al., 2004). This article will attempt to further contribute to the discussion, focusing on bicycle tourism in the United States. I shall examine the perceived public/private spaces of the American ${ }^{1}$ road network by placing the material history and ideology into the current automobility discourse and finally through a look at the 'escape' from such mobility through the bicycle tour. The urban bourgeoisie utilizes the bicycle for recreational purposes in part to reclaim a traditional sense of public place as well as to mediate the dominant assemblage of human and machine. This is not to say that it is the exclusive reason for purchasing and using a bicycle in the first place. To plainly say, bicycles exist as an alternative to the automobile would be to overly simplify these

20 objects both materially and socially. I will show through an empirical reading of bicycle tour journals that there is evidence of perhaps not full resistance to driving a car, but a temporary shift in epistemology toward automobility. It is by seeking what the dominant automobility is not that they are able to better come to terms with what it is.

The term 'automobility' is used playfully, blending the idea of self and 'objects or machines that possess a capacity for movement'. (Sheller \& Urry, 2000, p. 739). It should also be stressed that the term is a combination of autonomy and mobility, not necessarily requiring an automobile for its existence (Böhm et al., 2006). That said, the car is the dominant force in contemporary automobility, but others have looked at cycling (Fincham, 2006) and information technology (Miller, 2006) as alternatives.

$30 \quad$ Fincham uses bicycle messengers to illustrate the paradox of driving in the city: 'The bizarre reality is that the urban automobile is largely immobile, and it is this immobility that creates the space - and the demand - for bicycle messengers' (Fincham, 2006, p. 210). Where this article will depart from Fincham's is in its exploration of using the bicycle not as 'an apparent alternative to the motor-car as a provider of automobility in particular in urban environments' (Fincham, 2006, p. 209), but to escape the city and in part attempt to escape the dominant automobility regime. The term escape is used not to suggest a complete resistance in mobility, but should be read as a reminder that the bicycle tour is a form of tourism and recreation, that is a momentary departure from daily existence. Furthermore, I will show that within the sample of bicycle tours studied, the tour repositions the cyclists in American transportation networks to bring new perspectives on the human machine assemblage.

This assemblage of the human and machine, and the six components outlined by Sheller and Urry (2000, pp. 738-739) are utilized within the mobilities discourse to resist binary notions of the car as destroyer of urban society or the giver of freedom to the urban citizen. Within the American context, I wish to explore the third and fourth components of Sheller and Urry's (2000) six-part framework: the machinic complex and the quasi-private mobility that the car brings, respectively. 


\section{The Machinic Complex and the Frontier}

The automobility scapes of the American road are fully dependent upon time and history for any analysis, and as Horton et al. (2007) say, 'the bicycle and cycling need always and everywhere to be understood in relation to the societies in which they exist' (p. 7). The American freeway is a relatively recent creation that is far from universally accepted. The evolving structure of the road is in constant tension with the social norms and wants that construct and use it.

The twentieth century saw a change in the American road landscape with the mass production and popularity of the automobile. This originally was due in part to the improved transportation networks for the bicycle, but "new automobiles demanded new roads' (Jakle, 1990, p. 295). While this new mode of transportation soon led to problems of congestion and safety, the initial response was one of both pragmatism and aestheticism. Massive parkways were developed not only to move automobile traffic, but were designed for recreational driving and were extensively landscaped (Brown, 2005). This eventually changed. 'Local roads that once progressed tenuously over the landscape without obliterating anything gave way to wide, straight highways that sliced through hills, buried streams in culverts, filled in valleys with embankments, and stripped away trees' (Siddall, 1987, p. 314). The lack of regard for topography came from the fact that the engineer's vision of the freeway system won out over the planner's, i.e. an efficient movement of traffic at high speeds was the goal for road construction rather than incorporating the transportation network into the built landscape (Brown, 2005). The fact that efficient freeways were built instead of aesthetic networks is a result of the inability to quantify the latter (Brown, 2005) as well as the Eisenhower administration's push for a network to improve national security and the ability to evacuate a city in the threat of a nuclear attack (Jakle, 1990).

Americans have been fascinated almost to the point of cliché by the evolution of their road network and its connection with the 'American Dream' whatever its definition (Ireland, 2003). The American identity is caught between 'explicit mobility and implicit permanence' (Kemp, 1983, p. 157) in that the yearning for the fixed place of the home is in constant tension with the call of the open road (Cresswell, 1993). This is reflected in literature and nonfiction (Kerouac's On the Road, Steinbeck's Travels with Charley), film (Easy Rider, Cars, Thelma and Louise, see also Martin-Jones' [2006] reading of The Big Lebowski) and music (Steppenwolf, 'Born to be Wild'; Johnny Cash, 'I've Been Everywhere'). Such attention in media has led to recurring themes and the formation of identity. As Ireland writes in his analysis of the American road genre, 'Frederick Jackson Turner may have been quantitatively wrong in most of his conclusions, but it is clear that the myths and symbols of the frontier are enduring ones in the United States' (2003, p. 484). The importance of the idea of the frontier and a past way of life to Americans has led in part to the backlash toward the American Freeway. The freeway has allowed for the suburban lifestyle, in which the man of the house could enter the urban center to work and then return to his wife and children in the 'country' every evening (Jackson, 1985). Families could now distance themselves from a city while maintaining the benefits of living next to one (Fulton, 1997). This shift in housing and mobility has led to a shift away from the traditional ideas of public place (Sheller \& Urry, 2000), which I will explore below, but it has 


\section{M. W. Pesses}

also led to the idea of homogeneity of place or 'placelessness' (Relph, 1976) across the American landscape.

This conquering of the 'frontier' through the freeway and suburb also led to the idea that American identity must be embodied in order to know it and the road trip is crucial to knowing the scapes of America. A book like Blue Highways (Heat Moon, 1984) is an account of avoiding the freeway and its forcing of modernity upon the frontier, and its importance can be seen in how its ideas are reproduced and repositioned in other essays of the road (McMurtry, 2000; Morgan, 1999). Current social thought, however, has shown the problems with this and a push toward thinking of the world in terms of 'fixity' versus 'fluidity' (Cresswell, 2006; Massey, 2005), but the question should be asked, does someone undergoing a road trip give more credence to 'authentic' America or a more dynamic system of embodied mobilities? Cresswell critiques the prevalence of a 'sedentarist metaphysics' (2006, see Chapter 2 ) in which fixed place is given moral preference to mobility (while equally critiquing the romantic and Orientalist nature of some nomadic thought). Massey (2005) critiques that perceived fixity of place as well, seen as something 'vital to hold on to as "the global" spins its ever more powerful and alienating webs' (p. 5). She and Cresswell are right, of course, in attempting to transcend Enlightenment-inspired notions of space and place, but these notions still exist in the minds of many, which will be apparent in the tour journals below. Even in the highly mobile Western world, there is a sense that an authentic America does exist. The dialectic in American media, however, is the tension between the moral idea of fixed, rooted place that is uniquely American and the call of the frontier that demands mobility. The road trip is often seen as a means to wrestle with this tension, though reoccurring themes in American road media reproduce such conflicting ideas, even if the stories end in disenchantment or death.

\section{Homogeneous (Yet Uneven) Space?}

Regardless of how the road as authentic place is viewed, the perceived disappearance of the frontier wasn't the only issue Americans had with these high speed roads. In the late 1950s, a backlash against the freeway system began as urban citizens first saw the negative effects of such an efficient means of transportation. Issues like the loss of civil rights due to 'urban renewal' and environmental degradation were a direct result of the American freeway (Avila, 1998). The backlash against the uneven nature of the freeway system culminated in the 1970s with increased environmental regulation over development as well as the stagflation of the US economy (Brown, 2005). This led to increased regulation over road design and construction and all but ended the creation of new freeways (Brown, 2005, p. 26).

Horvath's 1974 work on 'machine space' echoes the tail end of this backlash and goes as far as to call the automobile the nation's 'sacred cow' (p. 168) as well as discusses the ecological nature of how the growth of 'automobile territory' acts much like erosion on urban place. He also provides some examples of resistance to the automobile; '...a car was buried at San Jose State College on Earth Day, 1970; a mayor who opposed highway construction was elected in Portland Oregon; the national Clean Air Act was passed; and controversy erupted over automobile safety. In hundreds of communities, public sentiment against the building of roads was 
aroused'. (1974, pp. 177-178). Social and environmental justice, as well as aesthetic taste, needed to be addressed in American transportation.

Around the same time of the backlash Horvath is describing, the Adventure Cycling Association organized the BikeCentennial Ride Across America of 1976, a coast-to-coast ride to celebrate the 200th birthday of the United States. The tour was a success for those involved and Adventure Cycling now boasts 42,000 members

AQ3 throughout the United States (Adventure Cycling Association, 2006). The history of the Association's mission is summed up in one sentence; 'These idealists not only wanted people to ride bicycles but also to travel very long distances by that mode and to see the nation's landscapes, history, and people from that vantage point' (D'Ambrosio, n.d.).

This backlash against the homogenizing machinic complex is an interesting context for the decision to ride a bicycle across the United States. My cursory analysis of this organization has not revealed whether the original tour was a direct challenge to the automobile or a shift in mobility for the purposes of experiencing the landscape in a new way. The website's message is clear however; the version of America seen from the bicycle saddle is one not able to be seen from the car, and there is a hint of 'authenticity' in this travel mode. A full analysis of this organization would obviously be beneficial to the greater discussion of cycling and society.

\section{Quasi-Private Mobility}

In addition to its materiality, automobility's social relations are also relevant in the context of the bicycle tour. As Urry states, 'the car is not simply a means of covering distances between A and B' (2006, p. 18). One facet of modern automobility is its 'quasi-private' nature in which the driver dwells within the car while still in a sense inhabiting the 'public' place of the road, but the mobility of the car and driver assemblage works against 'place' in general (Sheller \& Urry, 2000, p. 739). The world is abstracted and reduced to that what can be seen through the windshield (Sheller \& Urry, 2000, p. 747).

But to drive in the city is not as simple as viewing the landscape through framed glass. The landscape is further transformed through GPS and GIS technologies and models. The myriad technological advancements of the automobile 'all conspire to make the car into a kind of monad which increasingly refers to the world outside itself via heavily intermediated representations'. (Thrift, 2004, p. 51). So not only can the driver maintain his or her 'backstage', he or she is able to in a sense preserve the outside 'frontstages' through these intermediated representations (Goffman, 1959). The neat digital map on the computer screen (combined with limited vision of the windshield) presents a much more ordered and clean façade of the street and sidewalk than the embodied landscape of the pedestrian or cyclist (see Spinney, 2006). The litter, stray cats, even the homeless may be forced into the backstage of the street simply by not appearing on whichever screen the driver happens to be using at any given moment.

This blending of human and machine, combined with a mediated reality, has led to a debate on the public place and space of the urban street and sidewalk. In traditional forms of urban design, cities were planned 'using visual perspective to guide the walker through arcades and squares defined by fountains, to open, wider vistas 


\section{M. W. Pesses}

defined by the spatial vanishing points created by judiciously placed obelisks and domes' (Sheller \& Urry, 2000, p. 740). The presence of bodies on the street and sidewalk were seen not only as a part of urban life, but crucial to its safety as well (Jacobs, 1961). With the shift to the automobile comes a shift in designing cities as places of mobility and flow (see Jensen, 2007). Sheller and Urry argue early urban social thought tied 'civil society' to the material place of the city (2000, p. 740). This materialization of society and citizenship is then intrinsically embedded within and allowed by the movement between public and private places and spaces. It is the dominance of the automobile that is often viewed as destroying the public realm so 10 necessary for democracy, yet at the same time 'meeting places require that people get to them' (Sheller \& Urry, 2000, p. 742).

Further resisting the polemic of the evils of mobility and the car, J.B. Jackson proposed the idea that with the 'auto-oriented' landscape perhaps we as a society were moving past the need to demarcate public and private (1997 [1988]). 'Perhaps we can go one step further and see how in the vernacular world we are learning to share spaces, learning how to use them in a temporary way in order to overcome both the old-fashioned biological exclusiveness and the more modern overemphasis on competition and control' (Jackson, 1997 [1988], p. 77, emphasis in the original).

Regardless of one's view of mobility within an urban environment, the modern automobile presents a challenge (either perceived or real) to the socially important public place. A car can get one to the aforementioned public meeting, but the structural adaptation of the landscape to the car has reduced the need to enter the public sphere at all. The domestic garage, as Jackson points out, became 'internally integrated' (Jackson, 1997[1976], p. 123, emphasis in the original) in that one need not leave his or her house to enter the dwelling space of the car. Sheller and Urry further point to the presence of the 'drive-in' on the American landscape (2000, p. 746).

While this assemblage and its affect on the society have often been criticized, mobility is a part of American life (Cresswell, 1993), and more importantly, automobility is the dominant form. And while the flaws of this contemporary assemblage are readily apparent, a majority of Americans have accepted its daily presence. The creation of new freeways has been slowed, but the existing ones are still used and an important tool for traveling within the country. Ecological and social injustices have been brought to light, but no freeways have been torn down to right past wrongs. So the question becomes, "Which do we value more, a sense of place or a sense of freedom?' (Jackson, 1997 [1994], p. 250).

\section{Pedaling the (Public?) Landscape}

I wish to now discuss the bicycle tour as a means to understand this hybridization with the automobile and an attempt for the tourist to balance J.B Jackson's question by using the democratic freedom of mobility to seek the traditional notion of the public sphere. Thrift (2004) argues against using only one aspect of mobility, in his case, the determinism of technology upon mobility (e.g. GPS navigation), to fully understand it:

But I would argue that much of what actually characterizes everyday life - the creative moments arising out of artful improvisation on the spur of the moment 
- will continue to be opaque to system surveillance... It is these performative moments of narrative dissonance that we should be concentrating on. (p. 53)

While perhaps a more extreme form of 'everyday' dissonance than Thrift is calling attention to, the idea of the long-distance bicycle tour is a complete antithesis to the narrative of contemporary American automobility, yet still directly relevant to the concept. I have selected the long-distance bicycle tourist, rather than the utilitarian bicyclist, because of drastic change in mobility involved. The bicycle tour is characterized by multiple days covering many miles and constantly encountering new landscapes. These two factors eliminate the coping mechanisms that come with the daily bicycle commute (selecting the easiest route for time of day, familiarity with intersections, bicycle lanes, hazards, etc.) as well as increase the amount of time 'in the saddle'. Further, this is a recreational form of cycling, and does not represent a complete rejection of the automobile. The bicycle tour is a temporary repositioning of one's role in automobility.

This is not to say that other forms of vélomobility are not important in such a discussion. Recent work in the social sciences on bicycle travel has greatly advanced the discussion. Spinney (2007) argues against the very concept of 'non-place' and uses the bicycle to show how important the body is in understanding and experiencing the places of mobility. Fincham (2006) describes the bicycle messenger as one who is utilizing that mode of transport for economic means, as well as an attempt to reinterpret the dominance of automobility in Western cities. Furness (2007) shows how Critical Mass events (in which cyclists unite in large numbers to take back the streets) are 'a form of hermeneutic mobility that is intentionally designed to encourage a reinterpretation, and possible reevaluation, of both ideological norms that govern car culture and the practice of bicycling itself' (p. 302, emphasis in original). In these studies, the focus is on the utilitarian cyclist, that is, one who rides a bicycle for reasons other than recreation. What I will show is that another form of bicycling, the long-distance tour, is an attempt for a specific group of cyclists to reinterpret mobility's role in American civil society, while also seeking a lost ideal of the public sphere.

The website CrazyGuyOnABike.com hosts over 1,800 journals posted by bicycle tourists. In addition to hosting bicycle tour journals, the site provides a forum for discussion within the touring community on routes and equipment. It was developed by Neil Gunton in 2000 to initially post his own journal of touring across the United States in 1998 (Gunton, 2000), which he then turned into a website for others to do the same. The impact in the bicycle touring community has been tremendous, as evidenced by Gunton receiving the 2007 'Pacesetter Award' from the Adventure Cycling Association. Adventure Cycling refers to the website as being 'known throughout the bicycle travel industry as one of the best bicycle travel resources available' (Adventure Cycling Association, 2007).

CrazyGuyOnABike.com is a free site and allows long-distance bicycle tourists to post their progress from the road, assuming they can locate internet access. This provides the ability for near real-time updates, which in turn can help capture the raw emotion of the experience. Some tourists simply transcribe their handwritten journals after they have returned home. While many come from Adventure Cycling's routes, others simply involve a cyclist pointing his or her bicycle in a cardinal direction and 


\section{M. W. Pesses}

pedaling. The journals range from well-written musings on travel, politics, and life to terse updates on the day's mileage, weather, and mechanical failures. It is through the former that I explore the issues of repositioning automobility in relation to the landscape.

5 Out of over 1,800 journals on CrazyGuyOnABike.com, I first limited my potential sample to those occurring within the United States that made Gunton's 'featured' list (i.e. deemed worthy of special recognition for their descriptive quality in both text and photographs). This drastically reduced potential journals to 104, of which several were written by the same tourist. Redundant authors were omitted to ensure more variety in tour emotions and experiences. Of the 92 tourists to then choose from, I eliminated those riding in supported group rides. I also omitted any journals not covering at least 250 miles [ $402 \mathrm{~km}$ ]. This was an arbitrary cut, but the one I felt was necessary for a true engagement between the cyclist and the landscape. This left 54 journals, of which I chose 14 at random (though I attempted to maintain a balance of gender representation, see Appendix A).

I coded the sample journals looking for reoccurring themes pertaining to the mental and material elements of the tour. Three main themes were elucidated upon coding the journals. The first was that the bicycle tourists were negotiating existential authenticity. These tours were undertaken, quite simply, to see if they could be 20 done, both physically and mentally. The second was the sheer importance of the cultural and natural landscape in influencing the emotions and experience of the tour. Finally, the mediation of contemporary American automobility was a constant presence in the journals. These themes were then presented to the sampled bicycle tourists through follow-up e-mails and the sharing of this original research to avoid any misinterpretation or alienation (Bakardjieva \& Feenberg, 2000, p. 236).

It is this last theme found throughout the tour journals that I wish to explore below. More specifically, I shall focus on two aspects of the bicycle tour and road: the search for public place and the duality of the automobile dominant landscape.

\section{The Search for Public Place}

Maureen Kelly's journal (Girl, bike, road, summer, 2005) begins with a discussion of embodied automobilities. 'Before I started commuting by bicycle, I hadn't noticed the psychological effect of security and enclosure that is produced by going by car. Going by bicycle makes surrounding places and fellow travelers seem much more immediate' (Kelly, 2005, p. 3). When she first takes her fully loaded bicycle out on the road to test it the day before the tour begins, she picks up on the themes of property and mobility so crucial in American society (Cresswell, 1993; 1999). Without the familiar hybridization of the car-driver, as well as not having a permanently fixed (private) structure to return to at night, Kelly feels strange, "not quite "exposed"; maybe "nowhere to hide!"' $(2005$, p. 3$)$. Here we see the choice of embarking on the bicycle tour as a means to strip oneself of private place. The 'backstage' is limited to the inside of a small tent or a motel room.

In part, the bicycle tour is expressed to be a way of connecting with an 'authentic' version of America, one believed to be removed from the privatized homogeneity that the car produces. The tourists are looking for a Jeffersonian version of civil society, one of open spaces and an agrarian lifestyle that can only be threatened by urban 
spaces (Jacobson, 2002, p. 162). This is the frontier of the American road mythos. Whether such a place exists, or if in fact as McMurtry (2000) argues, exists everywhere due to the 'place' of light, is another discussion all together. It has been brought up within tourism studies that while a concept such as authenticity may be problematic and subjective, it should not be abandoned for the very reason that tourists themselves can think in these terms (Belhassen \& Caton, 2006). What is important in understanding the bicycle tour in the American middle class context is the idea that it is in part an attempt to (re)discover such an authentic place regardless of that place's actual past or current existence. Stuart Black cleverly uses dessert to explain the need to go in search of authentic America in his journal, Solo without pie (2005). Black actually uses pie to situate his tour in the spatio-temporal context of twenty-first century America:

When I was growing up back in the dawn of time, there were diners everywhere with fresh made pies. Huge varieties of pie. Coconut cream, apple, Dutch apple, cherry, blueberry, rhubarb - the list could be endless. But we live in the here and now - the world of Wally World [Wal-Mart] and corporate food. Why make a pie when a machine could make one for you. In the Iowan Missouri Valley, the Super Wally Worlds have closed down entire towns because it's 'cheaper' to go to Wally World than to shop at the expensive stores in town. When everyone goes to Wally World, there isn't anything to support the other businesses in town and so they close. It's a story that I saw repeatedly for 400 miles [644 km]. And so it means pie is hard to find. Almost impossible. But there is some to be had, you just have to look harder. (p. 14)

While Black does not address the full geopolitical and social forces of mobility in this passage, I feel it provides an excellent view into the need for some to use the bicycle tour to escape the networks and flows of global brands and homogeneous products. If we read 'pie' as the public, 'authentic' American town, the antidote for the globalized city, we see that in Black's mind it still exists. His opine for a past America echoes the academic concerns of Relph (1976) and Heidegger (1971). For Black, A Wal-Mart off an interstate freeway is incapable of providing a piece of authentic American life. The question of the subjectivity of that past America (what about the 'colored' citizens who weren't allowed to sit at the same counter to order that pie?) and the question of both the embodied and neoliberal places and spaces produced by Wal-Mart are not an issue for Black. His subjective leanings toward an ideal American diner reveal a need to escape the globalized urban centers and find a local place. Furthermore, a line like 'But there is some to be had, you just have to look harder' indicates that a rural, public version of America exists, but perhaps cannot be reached from the freeway, or even by automobile. Mobility, the right mobility, is the key in finding his authentic America.

There is a problem, of course, in assuming that urban place is a privatized wasteland full of social ills while rural and natural landscapes provide a welcoming public place. For these touring cyclists who are exploring the places of America, preconceived notions of the rural/urban and public/private divides are challenged. To return to Maureen Kelly's journal (2005), she ventures off of her main route to visit Myrtle Beach State Park, South Carolina for what she believes will be a natural experience, but: 
There were so many people, it boggled the mind. People everywhere. RVs, campers, cars. The park has its own concession open from 6:30 AM to 10:00 PM. It has laundry facilities. It has a hundred-yard long fishing pier. The campsites were two to a picnic table and fire ring. This here was an industrial recreational facility. (p. 11)

People surround her; 'this was definitely not the camping I was used to'. (p. 11). The passages in her journal focus on how modern automobility has dominated this place, through the massive presence of recreational vehicles (RVs) and the entrance to the park is only designed for motorized vehicles. What is particularly interesting is that there is an underlying feeling that the automobility that has allowed everyone to travel to Mrytle Beach has also brought with it the social ills of the city:

I regretted having reserved myself the 'most private' spot at the end of the road. I was happy that my next-door neighbor across the picnic table had a dog that growled at me. That was good. It would growl at other people, too

I walked in the store and saw the park ranger, with a very concerned look on her face, running out. As I was at the counter, there was a lady with a baby on her hip, describing her 7-year-old son to the clerk at the counter, who was on the radio.

A minute later her husband came in. 'Did he come back?' he asked his wife.

'No, you didn't find him?'

'I've been around the park four times,' he said.

'Oh, God,' the wife murmured, clearly desperate.

'How long has he been missing?' asked the clerk?

'An hour,' the wife said, trying not to cry.

All these people had been warning me about what could happen to a grown woman. I didn't want to think about what might happen to the little boy. (Kelly 2005, p. 11).

It isn't until a motorcycle tourist pulls into the campsite next to her that she begins to feel safe, and is able to express a connection to another human:

Just as things were looking grim, in rode a motorcyclist on a BMW. It was loaded up with saddle bags for touring. A kindred spirit, I thought, hopefully... We chatted about our respective tours while he set up camp. I got a good vibe from him, and felt a lot better about life in general. The cavalry had arrived. (p. 11).

While the modes of transportation are different, the choices of mobility are similar. He is using motorized transportation, though it is a different assemblage than the cardriver. His 'dwelling' is much more public without doors and windows, and Kelly sees this as making him a 'kindred spirit'. He appears to be seeking the same public spheres of America in order to negotiate the four-wheeled, enclosed dominance of the 
car. This is enlightening as it and other examples below reveal that for these cyclists, the bike is not (specifically) about environmental concerns and an attempt to escape modern technology. The embodied experience of not having an envelope of steel and glass when moving across America is a fundamental part of the touring experience, as in Kelly's case, is akin to riding a motorcycle across the country.

\section{Duality of the Automobility Landscape}

As the above example shows, the search for lost American public landscapes is fraught with duality. What may seem authentic and natural may in fact be contrived and commodified. There is more than simple irony at work here though; it would seem that Soja's socio-spatial dialectic (1980) is at work in that space itself is acting upon society.

Place can invoke emotion which can be augmented by mobility (Conradson \& McKay, 2007) and this is obvious in the accounts of these bicycle tourists. Of the 14 journals, MacHale's (2006) was the most the most (negatively) affected by place:

I rode around [Santa Cruz, California] for a while, and my initial impression was dim. People were unfriendly, and no one knew where anything was, even though they lived there. Then I pinch-flatted hopping a curb like an idiot, and had to fix that while ants crawled all over me in the hot sun. Then, twenty minutes later, the same tire was flat, and as I fixed it the wind blew my water bottle into the road where some shitnob in a minivan ran it over, even though they could have avoided it. I was tempted to run after it and slash the tires as it stopped at the next light, but I didn't want to leave my stuff unattended. Fucking Santa Cruz. (p. 3)

The 'touristy' nature of the city combined with (or perhaps because of) the various bicycle-related maladies leads to the blunt 'Fucking Santa Cruz'. But rather than a discussion of the affect of place, I wish to focus on the claim that 'people were unfriendly, and no one knew where anything was, even though they lived there' (MacHale, 2006, p. 3). While the friendliness of locals may vary, the lack of geographic knowledge is a common issue throughout the journals. The problem may not simply lie in the cardinal direction of a place or the route, but the actual time, effort, and mileage required in getting there. The automobile has managed to separate those giving directions from the actual terrain traversed to get to the destination. What is 'twenty minutes up the road' may be two hours, and what is 'just a mile or so' is really five. Dietrich (2005) uses her journal to summarize the lack of connection to the landscape:

The waitress confirmed my route choice, in the process telling me that 'We don't really have hills around here.'

Um, false.

Shortly after leaving the cafe, I decided that it would be fair to file this road under 'steep.' (p. 10) 


\section{M. W. Pesses}

This happens again the next day, and Dietrich sums up the situation simply, 'I asked for directions. The sweet girl at the desk was trying to be helpful, but didn't quite comprehend the differences between driving $a$ car and riding a bike' $(2005, \mathrm{p} .11$, emphasis added). Without utilizing the car-driver assemblage, the cyclists are in turn reproducing the material landscape. A different sense of place and space is created through the bicycle. To use Harvey's notions of the relative nature of space, 'We can create completely different maps of relative locations by differentiating between distances measured in terms of cost, time, modal split (car, bicycle, or skateboard) and even disrupt spatial continuities by looking at networks, topological relations (the optimal route for the postman delivering mail), and the like' (Harvey, 2006, p. 122, emphasis added). The space of the road is different for the driver and the cyclist, but the interesting point is that the cyclists never acknowledge the difference. They have all driven before (some even to get to the starting point of their bicycle tour), and their choice to use the bicycle positions the tourists in a unique situation, one in which they have experienced separate ends of the time-space compression of which Harvey is speaking. Spinney also shows how this shift in mobility can change a place, explaining how one cyclist experiences a place differently after riding a bus along the same street he usually travels by bike (2007, pp. 33-34).

The bicycle tourists may attribute the lack of geographical knowledge to ignorance or stupidity of the people, not to relative space or modal shifts. This attitude begins to reveal a certain duplicity found within many of the journals regarding anti-car/antifreeway sentiment; none more prevalent than in MacHale's (2006) journal of his trip along the California Coast. He makes five separate derogatory comments toward automobiles and their drivers, yet relies on a car three separate times during his 463mile $[745 \mathrm{~km}]$ trip. The bicycle tour is not solely a critique of the automobile, and it must be remembered that there is not a problem with using both motorized and nonmotorized transportation during a tour (see the discussion of Friedlander's journal below). However, a moral identity is invoked by MacHale when using different forms of transportation:

Past Carmel the Big Sur coast started, a land where the slopes of grassy mountains drop off of rocky cliffs and plunge dramatically into turquoise froth; a stretch of Highway 1 that is steep and winding and without generous shoulders. I wanted to make sure I was off the road a little earlier than usual, which would give me time time [sic] to soak in some of the gorgeous scenery and not have to worry about being obliterated by some gawking auto-tourist who doesn't have an ocean in their state. (MacHale, 2006, p. 5).

The 'auto-tourist' has no right to gawk, yet his description of the coastline indicates his own gawking. Later in the trip, while visiting family, he borrows his stepbrother's mother's car:

Scott can't drive for sordid legal reasons, so he handed me the keys to his mom's brand new turbo Forester, which I took with small reluctance, what with not having driven in a couple of weeks. Despite obliterating a small animal in a red spray of gore that filled up the rear-view mirror, the trip across town to get Vietnamese food turned out fine (except for the animal, that is). (p. 11) 
Note the use of 'obliterate' in each passage. While subtle irony may have been a work, there is a clear shift in identity. He is concerned with getting 'obliterated' by the 'gawking auto-tourist'; when MacHale is behind the wheel, the 'small animal' is 'obliterated' without any remorse.

It would be easy to bluntly label MacHale a hypocrite, but the ethics and morals associated with driving are not always simple. Sheller (2004) explains how the 'emotional geographies' of the automobile result in such ambivalence. Among the complex frames of meaning, Sheller argues, are the 'relationships between the car, the self, the family and friends, creating affective contexts that are also deeply materialized in particular types of vehicles, homes, neighborhoods, and cities'. (2004, p. 229). Not only is the automobile a convenient way to get around, but it is also an object that can reproduce spaces of domesticity, kinship, and identity. When MacHale borrows the Forester, it would appear that he is in a sense reclaiming a nonbicycle tourist identity that he left behind when he started the tour. Conversely, when he is on the bike, his identity is one of moral superiority to the landscape, which allows him to insult the 'tourists'.

The relative spaces of humanity are not the only duality at work; there is a material aspect at work as well. The infrastructure of American transportation is undoubtedly biased toward motorized modes. The extent of that bias is not readily seen from the mediated realities produced by the car windshield. Lefebvre speaks of 'mirages' and 'mirage effects' when speaking of the duality of space (1991, Chapter 3). The American road is no exception to this rule. More specifically, bridges, while involving a climb, would appear to be an inviting way to traverse a body of water or another route (e.g. a freeway overpass), but the cyclists were able to reveal the hostility of bridges across the country. This dual nature, that is while both useful for travel and almost impossible to travel across without the right mobility choice, is discussed throughout the journals, but I think best shown through the playful text and photography of Stuart Black's journal:

Lexington Bridge is not unlike the other bridges I crossed. Sure, it is narrow and old and about a half mile long.

That's not the problem. It's the only bridge for a hundred miles and so there is a lot of traffic on it.

That's not the problem. The problem with Lexington Bridge (remember that name) is that for its entire length, there is a gap between the road and the railing for the bridge.

In some spots, the gaps seem to be about half of the lane. From a bicycle seat these gaps look like they could swallow me, bike and panniers with only strips of skin remaining on the sharpened rebar where the concrete used to be.

And since the Missouri River is about 100 feet below the bridge, you'd get to contemplate how much pain there is in having your flesh ripped from you before you hit the water. Ouch! 
14 M. W. Pesses
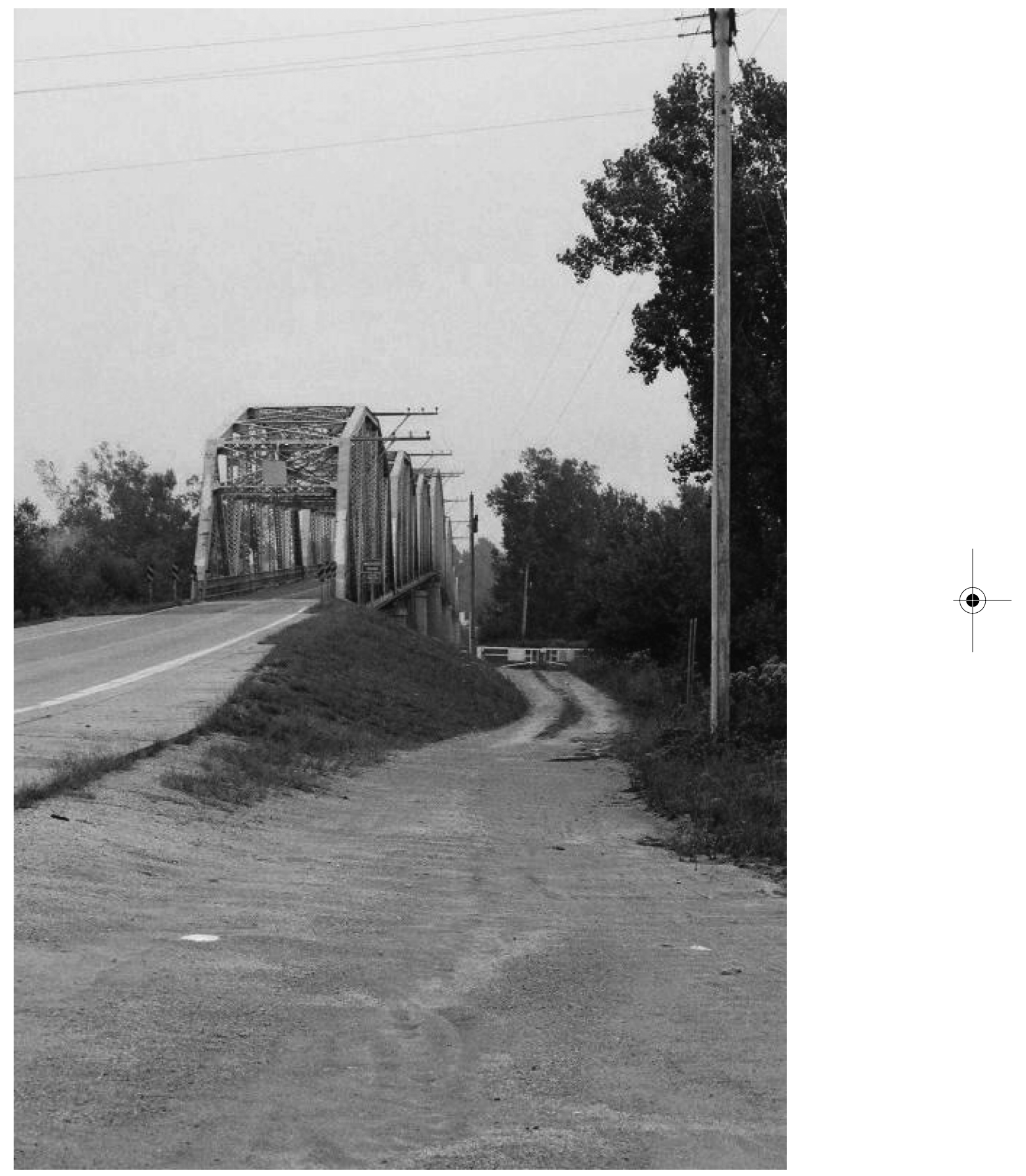

Figure 1. Lexington Bridge, photo by Stuart Black, 2005.
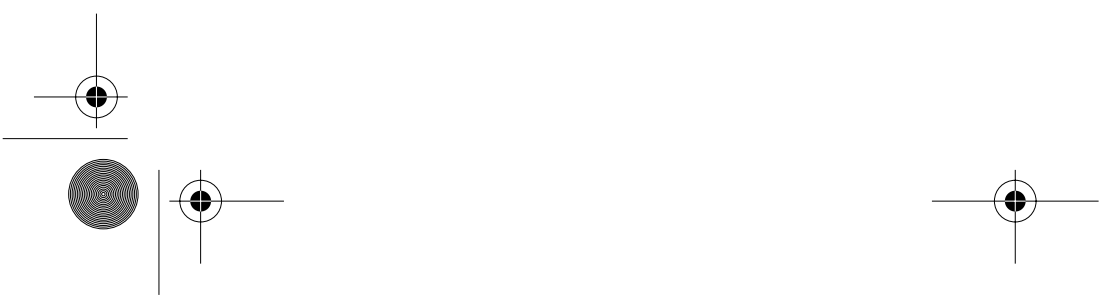


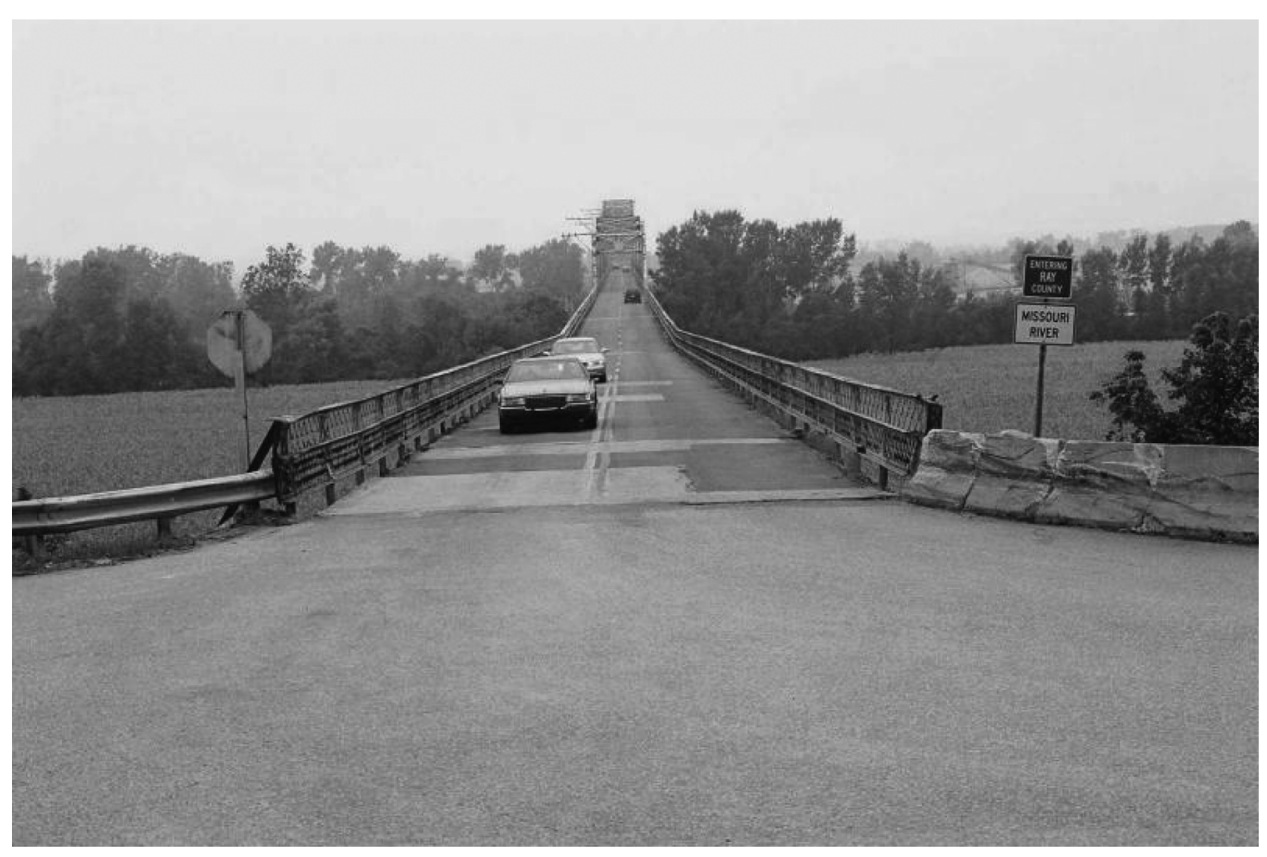

Figure 2. Lexington Bridge and traffic, photo by Stuart Black, 2005.

The only way to get across the Lexington Bridge is to screw up your courage, take a deep breath, try not to look through the holes and ride as hard and fast as you can as near to the center yellow line as possible. If any cars came up behind me, I didn't care. I wasn't about to move next to those damned holes for anything! (Black, 2005, p. 19)

This is an extreme case of a road not catering to non-motorized forms of transport, but the hazards of bridge crossings are a reoccurring theme. The duality of roads and their 'acceptable' uses in general is also seen throughout the journals:

The mist thickened to fog as we approached the turn back onto Highway One, where we also encountered a sign: "bicycles detour to Buellton". Huh? Why? Oh yes, the storm. It had probably caused one or more landslides that had closed down the shoulder or the right lane, but not about to be deterred from our course, we ignored the sign. (Friedlander, 2004, p. 12)

Jodi Friedlander goes on to write that there was in fact one section of Highway 1 where a landslide had covered the shoulder, eliminating the 'bicycling space' of the road, but 'that section was fast... and what little traffic there was had to delay their arrivals for a few minutes' (Friedlander, 2004, p. 12). So, while the obstacle was easily handled, those in control of the landscape did not feel that a bicycle belonged. It was not that the road was unable to be used, but that the mixing of automobiles and bicycles in the same road space was unacceptable. 
16 M. W. Pesses

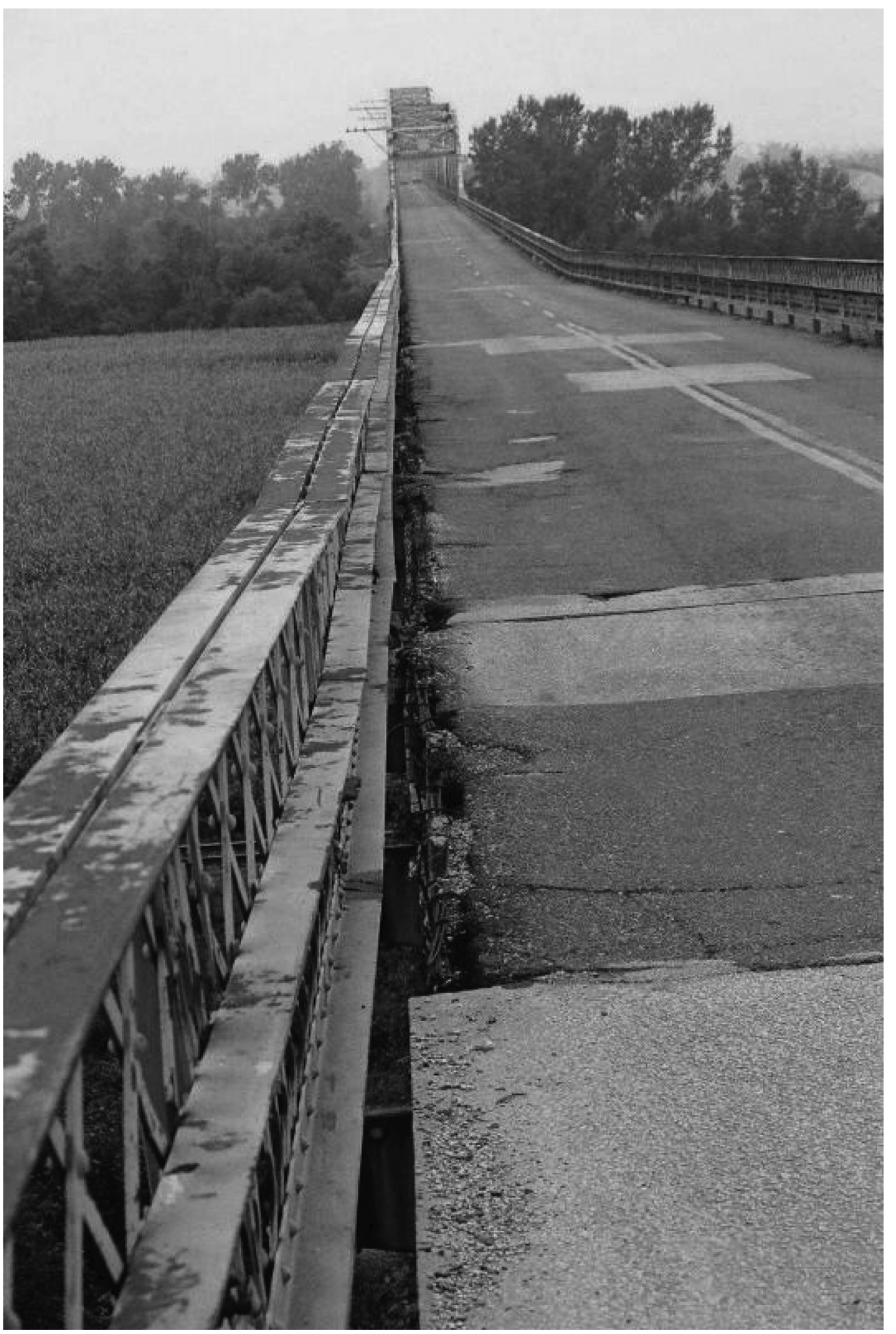

Figure 3. Lexington Bridge gap, photo by Stuart Black, 2005.

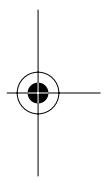

0

5




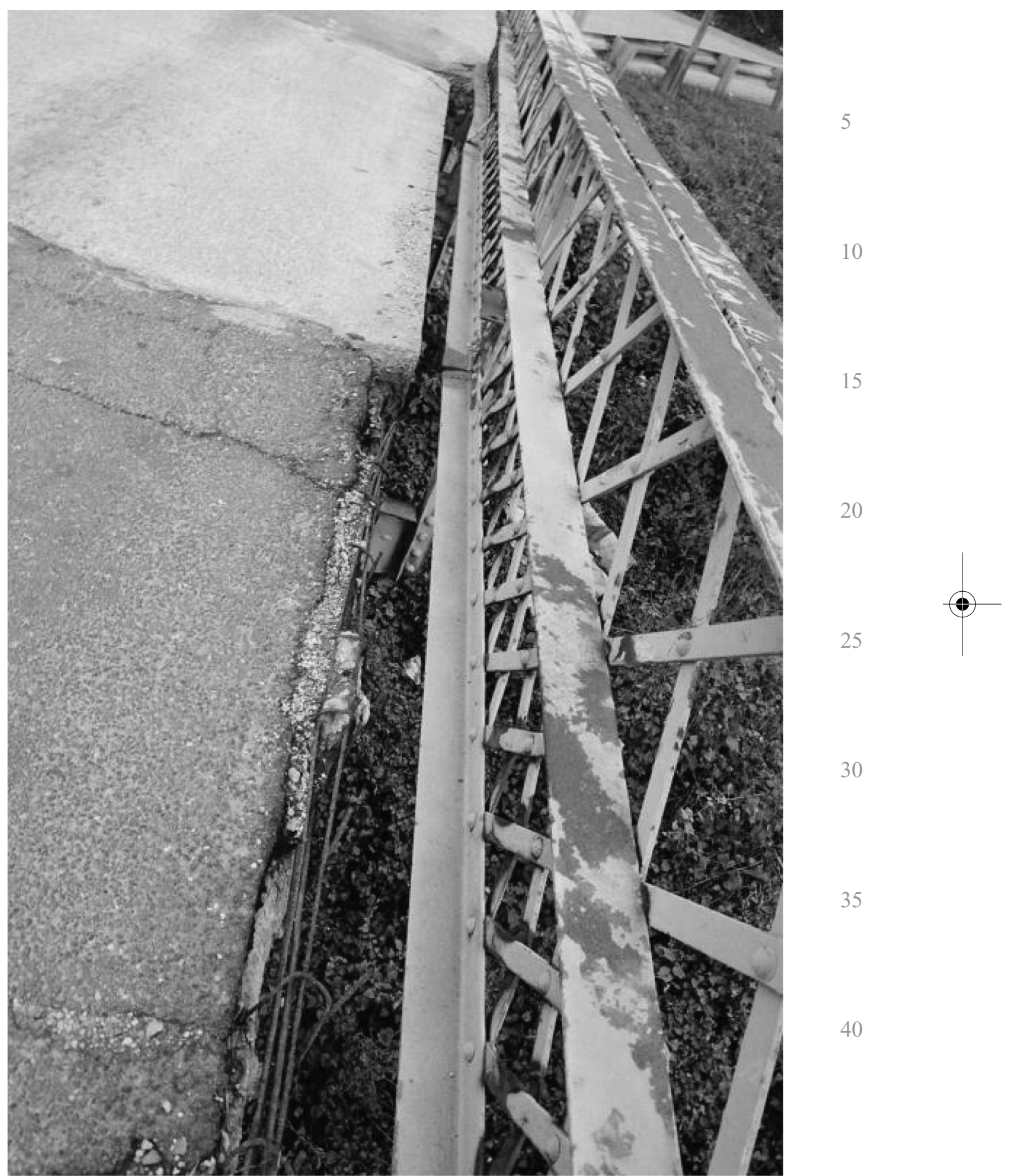

Figure 4. Lexington Bridge gap and rebar, photo by Stuart Black, 2005.
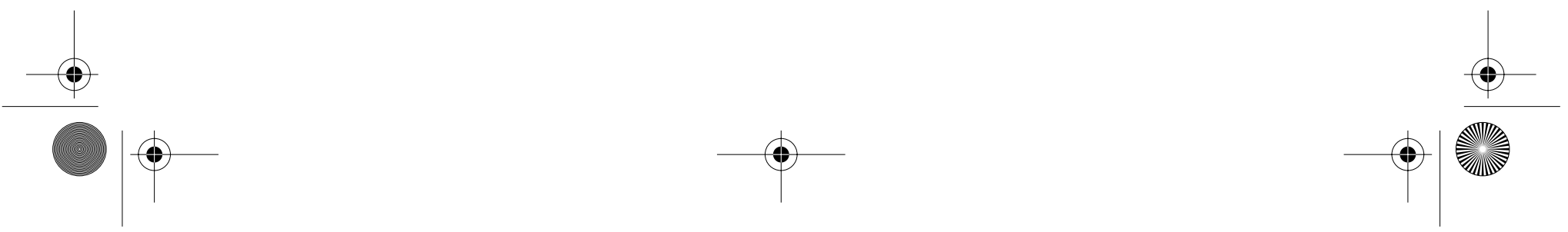


\section{M. W. Pesses}

In fact, even when the bicyclist is allowed to occupy the same landscape as the cardriver, he or she is seen as the 'other'. When riding through a construction zone on her tour, Matson (2004) is verbally abused for her mode of transport:

Finally the traffic moved through the mile-long zone at a good speed and I quickly fell behind. The flagman at the other end proceeded to let the oncoming traffic through before I got to the other end and some unfriendly rednecks in an oncoming pickup truck blared their horn and suggested that I "get off the f-ing road." Momma said there'd be days like this. (p. 10)

The bicycle tourists all encountered places and spaces where their non-motorized automobility was not welcome; either through the subtle exclusion of something like the RV strewn entrance to Myrtle Beach (i.e. creating a road that is so imposing to a cyclist that he or she will avoid riding on it), a lack of physical space as in 15 the Lexington Bridge, or a sign telling bicyclists to go out of their way so as not to ride on the 'public space' of the automobile's road. The cyclists negotiate these roads in small acts of defiance (as in Friedlander's above disregard of the sign) or by 'living to tell about it'. The journals themselves seem to be a form of catharsis for the cyclists; giving them a platform to write about their difficulties in traveling through automobile-dominated America. This not only leads to accounts of the duality of the road, but critiques of the automobile as well. Some are almost subtle, just pointing out the things that the motorists could not see, like when Stuart Black writes, 'And what was even better was that people in their cars couldn't see [the butterflies]. The only way to see them all was from the seat of a bike. That's how perfect a day can be! (2005, p. 14)'.

The two bicycle tourists covering the most mileage, Jamie Compos (6,620 miles $[10,654 \mathrm{~km}])$ and Joy Santee $(4,427$ miles $[7,125 \mathrm{~km}])$ do remark on the difficulty of returning to their old lives once their lengthy tours are over.

I'm looking down at roads from 30,000 feet up [flying home] and wondering how long it would take my two wheels to travel them, what stories might be had along their seemingly desolate shoulders...

And it's not that I mind my real life. In fact, I was pretty happy with it when I left, but I dread the transition back. I have to start remembering what day of the week it is... I'll find myself submitting back to a scheduled life with demands beyond eat/sleep/bike, demands and expectations from people other than me...

Of course, I'll sleep in the same spot most nights, have the luxuries of pillows, towels, and ice at hand, and not eat out of convenience stores or buy everything in single serving sizes. But I'll miss my new friends and the freedom of the road... [I] was reassured that the world isn't as bad of a place as the news and naysayers would have us believe.

In fact, it's quite a nice place when your pace is $10 \mathrm{mph} .$. (Santee 2006, p. 110)

The pace of which Santee speaks directly relates to the separate 'map' of the same area by choosing the bicycle over the car, or in this case the airplane (Harvey, 2006). 
It reveals that crime and terror do not lurk at every corner no matter what the news media may say, and in drafting such a map Santee is able to come to terms with her identity. She writes, ' $[\mathrm{I}]$ saw just a ribbon of the scenic wonders of this vast and varied country, learned something of people (myself included), beat up my body, fed my patriotism...' (Santee, 2006, p. 110) The landscape, the body, and personal and national identity all play a role in her reflection of the tour. Again, we also see a difficulty in completely disregarding modern life as well as completely embracing the romantic notions of cycling and rural America.

At the end of the tours, all of the cyclists returned to their previous lifestyles, though perhaps with a different outlook on mobility. And while the bicyclist may be choosing to not dwell within the car during the tour, there is an assemblage of sorts with the bicycle. Spinney (2007, pp. 34-35) notes how different bikes can shape, how a place is experienced, further suggesting that the bicycle is not a rejection of automobility, but rather a repositioning of the human-machine assemblage. In this case, the bicycle tourist will typically spare no expense for the machine that will take him or her across the continent. Rather than the high-end leather seats of an automobile, many tourists purchase high-end leather saddles to ensure comfort on the tour.

This talk of stepping outside of the dominant form of automobility should not suggest that this is a blunt challenge like that of Critical Mass (Furness, 2007). In some ways it helps reinforce the positive feelings toward the automobile. On the last day of her tour, Wanda Dietrich addresses the freedom given by the automobile (2005, p. 11). She has to call her husband to pick her up as she has to return to work the next day and cannot make it home in time by bicycle. The tour has been a positive experience, but the challenges faced have made her want to return home. 'This made for some interesting psychology. Because rescue was just hours away, I had a hard time working up the motivation for getting on the bike and out it to the wind and hills... I missed my freedom' (p. 11, emphasis added). She has had a positive tour and enjoyed the sounds and smells that can only be experienced by leaving the car at home, but at the same time she acknowledges just how powerful the automobile is. Note that this comment is in direct opposition to Santee's 'I'll miss my new friends and the freedom of the road' $(2006$, p. 110). The bicycle tour is not the same for all involved, and automobility does not mean the same thing for everyone. When looking at the American bicycle tour in terms of J.B. Jackson's question, as well as terms of automobility, it becomes clear that although ideas of authentic place and one national identity are part of the tour, the engagement of these concepts actually reveals the multiplicity of which Massey speaks (2005). The embodied mobilities of the bicycle tour allow for challenges to traditional notions of identity and automobility, even if those traditional notions were being sought in the first place.

\section{Conclusions}

When studying the bicycle, one must avoid the romantic images of the eco-friendly, civic-minded rider who chooses to resist the car. Sheller (2004, p. 222) argues against the 'rational choice' models of transportation when discussing the continued dominance of the automobile. 'Car consumption is never simply about rational economic choices, but is as much about aesthetic, emotional, and sensory responses to driving, as well as patterns of kinship, sociability, habitation, and work'. (Sheller, 


\section{M. W. Pesses}

2004, p. 222). The same can be said for those riding a bicycle. While the automobile is marketed as more than a way to get around town, high-end bicycles are marketed as symbols of speed, grace, dignity, and class. The choice to purchase a 'road bike', along with the special shoes, helmet, and colorful Lycra-spandex can almost be equated with purchasing a Porsche. It is more than mode of transportation; it is an identity.

If we agree that the choice to ride a bicycle is far from the rational analysis of environmental and economic factors, our exploration of this transport mode also cannot assume that it is a simple resistance to all things that are automobile. As 10 Fincham (2006, p. 221) beautifully puts it, 'what looking at cycle couriers (and arguably at cyclists more generally) suggests is not a project to end 'automobility' but rather the reverse, an attempt to reconstitute the principal object or technology through which it is to be understood'.

In many ways the bicycle offers a means to negotiate the quasi-private spaces of automobility in the urban environment. By stripping off the steel and glass envelope, the cyclist attempts to bring the street back to a public sphere. In the case of the Critical Mass events, the cyclist works to transform the urban street (Furness, 2007); in the case of the bicycle tourist, he or she leaves the city to find the perceived remaining public spaces and places in rural America. And just as Furness points out that such bicycle activism 'does not attract everyone to bicycling, but it is attractive to people that would otherwise be uninterested in bicycling' (2007, p. 312), the bicycle tour appears to be attractive to the bourgeoisie who are unhappy with the dominance of automobility, yet have little desire to completely do away with it. At the same time, it is also a way to challenge oneself physically and mentally. The cyclists are able to escape or alter their roles in the dominant automobility network for a week or a month at a time; relieving the pressures such a lifestyle creates. But for some, like Dietrich mentions above, modern automobility is not necessarily a bad thing. The ideas of public place and sense of freedom are played with by the cyclists. There is a specific idea of an authentic public place in America discussed in the tour journals, but there is

30 also ambivalence toward better living through modernity versus a romantic notion of Jeffersonian America.

The methods used to explore these themes provided a peek inside the minds of those choosing to tour by bicycle, but at the same time, may also limit some of the insight of bicycle tourists. Spinney comments on the problem of trying to 'represent the unrepresentable' (2007, p. 30) in reference to capturing the embodied experience of riding a bicycle. I would argue that these tour journals have provided insight into the touring experience, but obviously in-depth interviews and participant observation are in order, especially with touring cyclists not part of the CrazyGuyOnABike.com community. The fact that this is such an embodied experience means traditional narrative cannot be the sole means of exploring it.

A final note of caution is in order. I have generalized the mobility of an entire nation, useful for my purposes here, but by no means an acceptable end to this discussion. In this example, the bicycle is not simply 'a means of covering distances between A and B' (Urry, 2006, p. 18) any more than an automobile is. I have presented a picture of how one group of cyclists is able to utilize the bicycle tour to mediate the dominant automobilities of the United States. They often ride expensive machines built of carbon fiber components and aerodynamic frames. Another group 
of cyclists exists in the same urban centers - the working class and migrant workers who rely on cheaper bicycles to simply exist. They ride heavy frames with extraneous shock absorbers (added more for a specific look than comfort or function) purchased either from megastores like Wal-Mart or second hand from local bike resellers (see Koeppel, 2005 for a start to such a project). So, while the vélomobilities of the bike messenger (Fincham, 2006), the Critical Mass participant (Furness, 2007), bicycle racers (Spinney, 2006), environmentalists (Horton, 2006), and now the bicycle tourist have begun to be explored (not to mention historic and gendered [Dando, 2007; Mackintosh \& Norcliffe, 2007; Oddy, 2007; Simpson, 2007] accounts), it is time to turn our (critical) gaze upon the cyclist who rides on the sidewalk, without Lycraspandex, a helmet, or the benefit of the latest technologies. What social identities and mental lives do the most marginalized forms of bicycle mobilities create (Jensen, 2006)? Much work remains to be done on the cyclist who rides for economic benefit without much resulting economic benefit at the end of the day.

\section{Acknowledgments}

I must thank Ed Jackiewicz, Steve Graves, and Ron Davidson for tremendous support with this project, as well as the three anonymous reviewers whose comments greatly helped the ideas within this article, and of course, Sarah, Jack and Zoe...

\section{Notes}

1. I shall generalize and aggregate. The term 'American' is deliberately used in place of United States citizen, to produce an image of cohesion in a land of diversity. I do not argue that mobility is even and accessible to all, but instead utilize the 'ideal' or 'American Dream' of mobility for the purposes of this article.

\section{References}

Adventure Cycling Association. (n.d.) Available at http://www.adv-cycling.org/ (accessed 25 September 2007).

Adventure Cycling Association. (2007) 'Travel Award Winners'. Available at http://adventurecycling.org/news/2007/bikeawards.cfm (accessed 28 March 2008).

Avila, E. R. (1998) The folklore or the freeway: Space, culture, and identity in postwar Los Angeles, Aztlán, 23(1), pp. 15-31.

Bakardjieva, M. \& Feenberg, A. (2000) Involving the virtual subject, Ethics and Information Technology, 2(4), pp. 233-240.

Belhassen, Y. \& Caton, K. (2006) Authenticity matters, Annals of Tourism Research, 33(3), pp. 853-856.

Böhm, S., Jones, C., Land, C., \& Paterson, M. (2006) Introduction: Impossibilities of automobility, Sociological Review, 54(s1), pp. 3-16.

Brown, J. (2005) A tale of two visions: Harland Bartholomew, Robert Moses, and the development of the American Freeway, Journal of Planning History, 4(1), pp. 3-32.

AQ4 Brown, Jr., T. (1976) On an aesthetic of highway speed, JAE, 30(1), pp. 25-27.

Conradson, D. \& McKay, D. (2007) Translocal subjectivities: Mobility, connection, emotion, Mobilities, 2(2), pp. 167-174.

AQ5 Crazy Guy on a Bike. (n.d.) Available at http://www.crazyguyonabike.com (accessed 26 September 2007).

Cresswell, T. (1993) Mobility as resistance: A geographical reading of Kerouac's 'On the Road', Transactions of the Institute of British Geographers, 18(2), pp. 249-262.

Cresswell, T. (1999) Embodiment, power and the politics of mobility: The case of female tramps and hobos, Transactions of the Institute of British Geographers, 24(2), pp. 175-192. 


\section{W. Pesses}

Cresswell, T. (2006) On the Move: Mobility in the Modern Western World (London: Routledge).

D'Ambrosio, D. (n.d.) 'Our History', Adventure Cycling Association. Available at http://www.advcycling.org/whoweare/history.cfm (accessed 26 September 2007).

Dando, C. E. (2007) Riding the wheel: Selling American women mobility and geographic knowledge, Acme: An International E-Journal for Critical Geographies, 6(2), pp. 174-210.

Dant, T. (2004) The driver-car, Theory, Culture, and Society, 21(4/5), pp. 61-79.

Featherstone, M., Thrift, N. \& Urry, J. (Eds) (2004) Theory, Culture and Society, Special Issue on Automobilities.

Fincham, B. (2006) Bicycle messengers and the road to freedom, Sociological Review, 54(s1), pp. 208222.

Fincham, B. (2007) Bicycle messengers: Image, identity, and community, in: D. Horton, P. Cox \& P. Rosen (Eds) Cycling and Society, pp. 179-195 (Hampshire: Ashgate).

Fulton, W. (1997) The Reluctant Metropolis: The Politics of Urban Growth in Los Angeles (Point Arena, CA: Solano Press).

Furness, Z. (2007) Critical Mass, urban space, and vélomobility, Mobilities, 2(2), pp. 299-319.

Goffman, E. (1959) The Presentation of Self in Everyday Life (Woodstock, NY: The Overlook Press).

Gunton, N. (2000) Crazy guy on a bike: A personal account of a bicycle ride across America during the long, hot summer of 1998, Crazy Guy on a Bike. Available at http://www.crazyguyonabike.com/doc/ neil98 (accessed 12 June 2007).

Harvey, D. (2006) Spaces of Global Capitalism (London: Verso).

Heat Moon, W. L. (1984) Blue Highways: A Journey into America (New York: Fawcett Crest)

Heidegger, M. (1971) Building dwelling thinking, in: A. Hofstadter (Trans.) Poetry, Language, Thought, pp. 141-159 (New York: Harper Collins).

20 Horton, D. (2006) Environmentalism and the bicycle, Environmental Politics, 15, pp. 41-58.

Horton, D., Cox, P. \& Rosen, P. (2007) Introduction: Cycling and society, in: D. Horton, P. Cox, \& P. Rosen (Eds) Cycling and Society, pp. 1-23 (Hampshire: Ashgate).

Horvath, R. J. (1974). Machine space, The Geographical Review, 64(2), pp. 167-188.

Ireland, B. (2003) American highways: Recurring images and themes of the road genre, The Journal of American Culture, 26(4), pp. 474-484.

Jackson, J. B. (1997 [1976]) The domestication of the garage, in: H. L. Horowitz (Ed) Landscape in Sight, pp. 118-125 (New Haven: Yale).

Jackson, J. B. (1997 [1988]) The accessible landscape, in: H. L. Horowitz (Ed) Landscape in Sight, pp. 6877 (New Haven: Yale).

Jackson, J. B. (1997 [1994]) Roads belong in the landscape, in: H. L. Horowitz (Ed) Landscape in Sight, pp. 249-254 (New Haven: Yale).

Jackson, K. (1985) Crabgrass Frontier: The Suburbanization of the United States (New York: Oxford).

Jacobs, J. (1961) The Death and Life of the Great American Cities (New York: Random House).

Jacobson, D. (2002) Place and Belonging in America (Baltimore, MD: Johns Hopkins).

Jakle, J. A. (1990) Landscapes redesigned for the automobile, in: M. P. Conzen (Ed) The Making of the American Landscape (Boston: Unwin Hyman).

Jensen, O. B. (2006) 'Facework', flow and the city: Simmel, Goffman, and mobility in the contemporary city, Mobilities, 1(2), pp. 143-165.

Jensen, O. B. (2007) On the fluid production of meaning and identity: Urban mobility as meaningful everyday life practice. Presented at the Annual meeting of the Association of American Geographers, 17-21 April in San Francisco, California, USA.

Kemp, L.W. (1983) Putting down routes: Folk and popular perceptions of the road, Western Folklore, 42(3), pp. 157-178.

40 Koeppel, D. (2005) 'Invisible Riders' Bicycling.com http://www.bicycling.com/article/1,6610,s1-3-1213639-1-P,00.html (accessed 18 April 2008).

Lefebvre, H. (1991) The Production of Space (Oxford: Blackwell).

Mackintosh, P. G. \& Norcliffe, G. (2007) Men, women, and the bicycle: Gender and social geography of cycling in the Late Nineteenth-Century, in: D. Horton, P. Cox \& P. Rosen (Eds) Cycling and Society, pp. 153-177 (Hampshire: Ashgate).

Martin-Jones, D. (2006) No literal connection: images of mass commodification, US militarism, and the oil industry in The Big Lebowski, Sociological Review, 54(s1), pp. 131-149. 
McMurtry, L. (2000) Roads: Driving America's Great Highways (New York: Touchstone).

Miller, J. H. (2006) Virtual automobility: Two ways to get a life, Sociological Review, 54(s1), pp. 193-207.

AQ4 Morgan, J. (1999) The Distance to the Moon: A Road Trip into the American Dream (New York: Riverhead).

Morris, C. O. (1909) The truth about the automobile, Country Life in America, January, pp. 259-260.

Oddy, N. (2007) The flaneur on wheels? in: D. Horton, P. Cox \& P. Rosen (Eds) Cycling and Society, pp. 97-112 (Hampshire: Ashgate).

Relph, E. (1976) Place and Placelessness (London: Pion).

Sheller, M. (2004) Automotive emotions: Feeling the car, Theory, Culture, and Society, 21(4/5), pp. 221-242.

Sheller, M. \& Urry, J. (2000) The city and the car, International Journal of Urban and Regional Research, 24(4), pp. 737-756.

Siddall, W. R. (1987) Transportation and the experience of travel, Geographical Review, 77(3), pp. 309-317.

Simpson, C. S. (2007) Capitalizing on curiosity; Women's professional cycle racing in the Late-Nineteenth Century, in: D. Horton, P. Cox \& P. Rosen (Eds) Cycling and Society, pp. 47-65 (Hampshire: Ashgate).

Soja, E. W. (1980) The socio-spatial dialectic, Annals of the Association of American Geographers, 70(2), pp. 207-225.

Spinney, J. (2006) A place of sense: A kinaesthetic ethnography of cyclists on Mont Ventoux, Environment and Planning D: Society and Space, 24, pp. 709-732.

Spinney, J. (2007) Cycling the city: Non-place and the sensory construction of meaning in a mobile prac-

AQ4 tice, in: D. Horton, P. Cox \& P. Rosen (Eds) Cycling and Society, pp. 25-45 (Hampshire: Ashgate).
Thrift, N. (2004) Driving in the city, Theory, Culture, and Society, 21(4/5), pp. 41-59.

Urry, J. (2004) The 'system' of automobility, Theory, Culture and Society, 21(4/5), pp. 25-39.

Urry, J. (2006) Inhabiting the car, Sociological Review, 54(s1), pp. 17-31. 


\section{M. W. Pesses}

\section{Appendix A. Sampled Bicycle Tour Journals}

Black, S. (2005) Solo without pie: Wandering the Lewis and Clark Trail, Crazy Guy on a Bike. Available at http://www.crazyguyonabike.com/doc/cyccommute2003 (accessed 25 September 2007).

Bruckdorfer, R. (2006) Touring again: A tour from Baltimore to Western Maryland via Catoctin Mountain, Appalachian Spine and C\&O Canal Towpath, Crazy Guy on a Bike. Available at http:// www.crazyguyonabike.com/doc/2000 (accessed 25 September 2007).

Compos, J. (2006) Bicycling across America: Riding from the Outer Banks, NC to San Francisco, CA, Crazy Guy on a Bike. Available at http://www.crazyguyonabike.com/doc/jamie2006 (accessed 25 September 2007).

Dietrich, W. (2005) Spring fever 2005: An early season ride home from Minnesota to Nebraska, Crazy Guy on a Bike. Available at http://www.crazyguyonabike.com/doc/springfever2005 (accessed 12 June 2007).

Estes, W. (2004) Wayne's Yellowstone/Grand Teton bike tour: A tour in northwestern Wyoming, plus a bit of Montana, Crazy Guy on a Bike. Available at http://www.crazyguyonabike.com/doc/ Wyoming2004 (accessed 17 August 2007).

Friedlander, J. (2004) A California coastal tour: Sonoma County to Santa Barbara: Mirth, wind, and fire... oh yes, and lots of water, Crazy Guy on a Bike. Available at http://www.crazyguyonabike.com/doc/736 (accessed 17August 2007).

Goldberg, D. (2002) Boston to Oregon: A cross-country celebration, Crazy Guy on a Bike. Available at http://www.crazyguyonabike.com/doc/Denise2002xc (accessed 12 June 2007).

Gunton, N. and C. Sakamoto (2003) Pedaling to the mall: A bicycle ride from Ashland, WI to the mall at Fargo, ND (and back again), Crazy Guy on a Bike. Available at http:/www.crazyguyonabike.com/ doc/PedalingToTheMall (accessed12 June 2007).

Haubert, R. (2001) California! An amazing adventure through the best of the Golden State, Crazy Guy on a Bike. Available at http://www.crazyguyonabike.com/doc/richtour2001 (accessed 8 June 2007).

Kelly, M. (2005) Girl, bike, road, summer: Hogtown to Beantown and back, Crazy Guy on a Bike. Available at http://www.crazyguyonabike.com/doc/1016 (accessed 8 June 2007).

MacHale, B. (2006) Going number one: San Francisco to Ventura, Crazy Guy on a Bike. Available at http://www.crazyguyonabike.com/doc/2105 (accessed 8 June 07).

Matson, L. (2004) Portland to Missoula Solo '04: A solo adventure through the Northwest along the TransAmerica Route, Crazy Guy on a Bike. Available at http:/www.crazyguyonabike.com/doc/ 1td2004 (accessed 22 August 2007).

Santee, J. (2006) CircumTrektion: TransAm 2006, Crazy Guy on a Bike. Available at http:// www.crazyguyonabike.com/doc/circumtrektion (accessed 22 August 2007).

Wayland, S. (2006) The wages of spin: Riding to Las Vegas through the Valley of Death, Crazy Guy on a Bike. Available at http://www.crazyguyonabike.com/doc/2163 (accessed 25 September 2007). 